\title{
DISCIPLINA DE EDUCAÇÃO AMBIENTAL: CONSTRUÇÃ̃O DO SABER DOCENTE NO CURSO DE CIÊNCIAS BIOLÓGICAS DA UNIVERSIDADE FEDERAL DE UBERLÂNDIA (UFU)
}

Melchior José Tavares Júnior ${ }^{1}$

Resumo: $O$ objetivo desse texto é sistematizar um saber docente sobre a disciplina Educação Ambiental no curso de Ciências Biológicas da Universidade Federal de Uberlândia (UFU), uma década após sua inserção na grade curricular, em caráter obrigatório. Os resultados dessa atitude reflexiva sugerem que a disciplina (1) garante o contato do graduando com o tema, oferecendo uma bagagem teórico-metodológica; (2) quando oferecida logo no início do curso, vários alunos decidem pelo tema em seu Trabalho de Conclusão de Curso, bem como pela pós-graduação na área; (3) é oportuna para a comunicação de novas oportunidades profissionais para os biólogos. Apesar dos alcances da forma disciplinar, os limites desse único modo de abordagem podem comprometer a prática profissional dos estudantes, motivo suficiente para discussão permanente pelas instituições formadoras.

Palavras-chave: Educação Ambiental; Disciplina; Ensino Superior.

Abstract: The objective of this text is to systematize a teaching knowledge about the Environmental Education discipline in the Biological Sciences course of the Federal University of Uberlândia (UFU), a decade after its insertion in the curriculum, on a mandatory basis. The results of this reflexive attitude suggest that the discipline (1) guarantees the student's contact with the theme, offering a theoretical and methodological background; (2) when offered right at the beginning of the course, several students decide on the theme in their Course Conclusion Paper, as well as on the postgraduate course in the area; (3) it is opportune to the communication of new professional opportunities to the biologists. Despite the reaches of the disciplinary form, the limits of this single approach can compromise the students' professional practice, reason enough for permanent discussion by the training institutions.

Keywords: Environmental Education; Discipline; Higher Education.

\footnotetext{
1 Universidade Federal de Uberlândia. E-mail: profmelk@hotmail.com.

Link para o Lattes: http://lattes.cnpq.br/9852264647189506.
}

revista brasileira 


\section{Introdução}

A Educação Ambiental brasileira vem registrando um processo de institucionalização no sistema público de ensino. O ponto de partida foi a atual Constituição Federal, publicada em 1988, seguido dos Parâmetros Curriculares Nacionais (PCN's), publicados em 1997, a Política Nacional de Educação Ambiental (PNEA), publicada em 1999, e as Diretrizes Curriculares Nacionais (DCN's) para Educação Ambiental, publicada em 2012. Embora o conceito tenha sido estabelecido na década de 1970, postulando a articulação das disciplinas para uma abordagem integral da realidade, essa compreensão e prática educativa na educação formal ainda não foram alcançadas.

$\mathrm{Na}$ Educação Básica, fenômenos recentes chamam nossa atenção e evidenciam a complexidade do assunto. Por exemplo, com base no princípio constitucional que estabelece que a educação para defesa e a preservação do meio ambiente pelas futuras gerações é dever do Estado, câmaras municipais e estaduais por todo o país vêm propondo a inclusão de uma disciplina de Educação Ambiental em suas redes de ensino (GUIDO; TAVARES JR., 2009); no Senado Federal, está em tramitação o projeto de lei 221/2015, que propõe a obrigatoriedade da disciplina no ensino fundamental e médio.

Desempenhando seu papel de forma mais responsável, a Educação Ambiental permanece como objeto de discussão no Ensino Superior, levada adiante por aqueles professores que, conforme Reigota (2007), se dedicam ao assunto e conquistam importantes espaços de ensino e pesquisa no ambiente acadêmico. Simultaneamente ao trabalho docente para consolidação da Educação Ambiental no ensino superior, muitas instituições universitárias têm implementado programas relacionados à questão ambiental, nos quais a oferta do tema na forma disciplinar/interdisciplinar se faz presente como um dos objetivos das propostas apresentadas (ALENCAR; BARBOSA, 2018). É o caso da Política Ambiental da Universidade Federal de Uberlândia (UFU), publicada em 2012. Tendo como referência a Constituição Federal de 1988, a proposta recomenda que a Educação Ambiental seja desenvolvida principalmente de forma transdisciplinar, embora outras formas de inserção da temática, como uma disciplina, também possam ser utilizadas.

De um modo geral, nesse momento histórico, os projetos pedagógicos dos cursos de graduação na universidade brasileira ainda se mostram predominantemente disciplinares, o que sugere que a Educação Ambiental venha a ser inserida principalmente por meio de uma disciplina no currículo. Trata-se de uma situação entre o ideal e o real, na qual é mais provável que as disciplinas pelo país afora sejam sobre Educação Ambiental e não de Educação Ambiental.

Nosso objetivo nesse texto é descrever e refletir sobre a oferta da Educação Ambiental na forma de uma disciplina no curso de graduação em Ciências Biológicas da Universidade Federal de Uberlândia, um exercício justo aos colegas professores que tanto se esforçaram nos últimos 20 anos para a concretização dessa possibilidade. Além de expor um roteiro para a disciplina, 
buscamos refletir: o que é abordado na disciplina? O que se revela no cotidiano da mesma? Encontra-se adequadamente situada na grade curricular? Sua carga horária é suficiente? É uma forma que aglutinará forças e antecederá à forma interdisciplinar? O que dizem os alunos?

Não se trata apenas de uma atitude reflexiva (SCHÖN, 2000) antes, durante e após a prática docente, mas também de um esforço em registrar sistematicamente o saber docente que esperamos ter produzido ao longo de quase uma década como docente desta disciplina. Conforme Tardif (2007), "pode-se definir o saber docente como um saber plural, formado pelo amálgama, mais ou menos coerente, de saberes oriundos da formação profissional e de saberes disciplinares, curriculares e experienciais" (p. 37).

Se o exercício de sistematizar nosso saber docente obtiver êxito, pretendemos, sobretudo, contribuir com a própria constituição da Educação Ambiental como conhecimento ${ }^{2}$, ampliando as possibilidades de construção de um saber ambiental, compreendido da seguinte forma por Leff (2001):

O saber ambiental é mais do que um conhecimento composto pelo amalgama dos saberes atuais ou pela conjunção de diversas disciplinas para resolver um problema concreto. $\mathrm{O}$ saber ambiental questiona os paradigmas dominantes do conhecimento para construir novos objetos interdisciplinares de estudo.

De um modo geral, os estudos acadêmicos que versam sobre o ensino de um determinado campo de conhecimento na forma disciplinar tendem a apontar os limites dessa forma de trabalho pedagógico. Entretanto, nesse texto, procuramos acolher também as possibilidades de uma disciplina de Educação Ambiental, sendo pertinentes aqui os conceitos de disciplina e teoria.

Para pensadores como Sommermann (2003); Chervel (1990) e Santomé (1998), uma disciplina é um espaço legitimado pela comunidade científica com o fim específico de estabelecer uma comunicação entre certa área do conhecimento e os estudantes a partir de um procedimento regido por protocolos da área em questão. Trata-se, portanto, de um território de trabalho delimitado e caracterizado por determinado ângulo de visão, um ambiente bastante consolidado no espaço e no imaginário acadêmico. Sobre teoria, Praia; Cachapuz; Gil-Pérez (2002, p. 131) afirmam:

\footnotetext{
${ }^{2}$ Ao nos referimos à Educação Ambiental como conhecimento e não campo ou área de conhecimento, evitamos delimitar o que fica dentro e fora de um determinado campo ou área, o que é coerente com o princípio interdisciplinar da Educação Ambiental.
} 
As teorias científicas, enquanto versões em construção ao longo dos tempos, evidenciam as mudanças e a complexidade das relações entre os conceitos, assim como as próprias visões das comunidades científicas de determinada época. Elas são as peças essenciais na construção de uma determinada área científica, o que em grande parte determina os problemas a investigar, as metodologias a desenvolver e os referenciais para avaliar os resultados da investigação. Não são intemporais, mas também não vagueiam e mudam ao longo dos tempos sem orientação. Em cada época, determinada (s) disciplina(s) científica(s) desenvolve(m)-se através de teorias centrais. Importa que elas não se apresentem descaracterizadas no ensino, como simples descrições e às quais o professor dedica pouco tempo - às vezes não mais do que simples definições.

Note-se a estreita e desafiadora relação entre as ideias de teoria, disciplina, saber ambiental e saber docente. Não é por acaso que apresentamos aos alunos que se trata de uma disciplina sobre e não de Educação Ambiental. Embora concordemos com a natureza interdisciplinar do tema definida desde Tbilisi, e para ela sempre buscamos caminhar, neste momento pretendemos estimar e aprender com o que temos em mãos, ou seja, a oferta disciplinar do tema. Um exercício semelhante ao proposto nesse texto foi desenvolvido por Martins et al. (2015). No trabalho citado, os autores partem do conhecimento prévio dos alunos para a construção e execução de um programa para a disciplina Educação Ambiental.

\section{A disciplina no Instituto de Biologia/UFU}

Em 2006, em atendimento às novas diretrizes do Ministério da Educação (MEC) estabelecidas em 2002, o curso de Ciências Biológicas da UFU passou a ter um novo projeto pedagógico. Nessa oportunidade, a disciplina Educação Ambiental foi incluída no projeto pedagógico, nas modalidades Licenciatura e Bacharelado, na condição obrigatória, no sétimo período do curso, tendo como requisito a disciplina Ecologia. No atual projeto pedagógico, realocamos a disciplina para o primeiro período, não tendo mais pré-requisito, obviamente. Essa mudança ocorreu diante de um dilema. No sétimo período os alunos estão mais maduros para uma disciplina com essas características. Porém, a disciplina estava sendo apresentada a eles tarde demais e os mesmos já se encontravam comprometidos com as diversas áreas das Ciências Biológicas - Bioquímica, Parasitologia, Imunologia, Genética, Botânica, Ecologia, Zoologia e outras, não tendo assim a oportunidade de seguir sua formação em nível de pós-graduação na trilha da Educação Ambiental. Nossa avaliação atual é que a disciplina deve permanecer no primeiro período. Nesse sentido, decidimos que uma das aulas da disciplina seria justamente a Pós-graduação em Educação Ambiental no Brasil, fazendo uma reflexão sobre os limites e as possibilidades de mestrado e doutorado em 
Educação Ambiental no país e o panorama dos concursos para docente nos dias de hoje e as expectativas para os próximos anos.

Recentemente a disciplina Educação Ambiental passou a receber alunos dos cursos de graduação em Engenharia Ambiental, Medicina Veterinária e Estatística, os quais que se matricularam na disciplina, contada em seus currículos como optativa, um reflexo da exigência do MEC, em cumprimento à PNEA. Semestralmente, a disciplina recebe em torno de 10 alunos em cada um dos dois turnos, a maioria veteranos, próximos à formatura. Alguns procuraram a disciplina para cumprir a carga horária necessária para a integralização curricular, outros desejavam ter um contato maior com o tema. $A$ satisfação dos alunos com a disciplina bem como a surpresa em ter que desenvolver atividades de Educação Ambiental nos estágios obrigatórios causou um grande interesse pela disciplina a ponto de cogitarmos uma turma para os ingressantes e outra para os demais cursos. A oferta de uma disciplina para alunos de outros cursos é um assunto ainda sem desdobramento, dentre outros pelo fato de os ingressantes terem sido beneficiados porque puderam discutir com os veteranos da Engenharia Ambiental sobre Estudos de Impacto Ambiental (EIA), Relatórios de Impacto Ambiental (RIMA), relação com a comunidade, etc. Essa interação só foi possível porque abrimos espaço na disciplina para que pudessem expor o que estavam vivenciando nos estágios obrigatórios.

Ao longo dessa primeira década de oferta da disciplina, muitos alunos que por ela passaram, alguns deles da Engenharia ambiental, nos procuraram para desenvolver seu Trabalho de Conclusão de Curso (TCC) com o tema Educação Ambiental, alguns se encontram em lista de espera para serem orientados. Até 0 momento, orientamos 15 graduandos, os quais desenvolveram os seguintes temas:

$\checkmark$ A percepção ambiental de alunos e professores do Ensino Fundamental da Escola Estadual Governador Clóvis Salgado, Município de Ituiutaba/MG.

$\checkmark$ Educação Ambiental em escolas públicas de Ituiutaba: práticas e tendências.

$\checkmark$ Educação Ambiental na Faculdade de Ciências Integradas do Pontal (FACIP).

A contribuição do poder público municipal no desenvolvimento da Educação Ambiental Escolar.

$\checkmark$ Desenvolvimento da Educação Ambiental Escolar: uma Investigação sobre o Livro Didático de Biologia.

$\checkmark$ As Novas Tecnologias da Informação e Comunicação (NTIC) no Desenvolvimento da Educação Ambiental Escolar.

$\checkmark$ Abordagem do tema Bem-estar dos animais domesticados errantes em alguns cursos de graduação da universidade Federal de Uberlândia. 
$\checkmark$ Educação Ambiental no curso de Ciências Biológicas da UFU: a pesquisa e a institucionalização do tema na formação dos biólogos.

$\checkmark$ Educação Ambiental no curso de Pedagogia da Faculdade de Educação da Universidade Federal de Uberlândia.

$\checkmark$ Formação Continuada em Educação Ambiental: um olhar sobre o Centro Municipal de Estudos e Projetos Julieta Diniz (CEMEPE) - Uberlândia/MG.

$\checkmark$ A Educação Ambiental na escola: um olhar sobre projetos desenvolvidos em algumas escolas públicas de Araguari/MG.

$\checkmark$ Educação Ambiental não formal na proteção da fauna silvestre: reflexões sobre uma exposição fotográfica.

$\checkmark$ O programa escola água cidadã (PEAC) sob a ótica dos estagiários egressos.

$\checkmark$ Educação Ambiental nas empresas: um olhar para a divulgação digital.

$\checkmark$ Educação Ambiental no curso de Engenharia Ambiental: ocorrência e formas de abordagem.

Todos os TCC's listados acima foram apresentados em eventos científicos na forma de comunicação oral, alguns publicados em periódicos qualis B. Dentre esses autores, três já se encontram em programas de mestrado em educação, sob nossa orientação, com estudos em Educação Ambiental.

Esse movimento tem possibilitado o retorno de vários desses ex-alunos à disciplina na condição de palestrantes de suas pesquisas. Essa retroalimentação pode contribuir para (1) a construção do saber ambiental (LEFF, 2001); (2) para a maturidade profissional desses egressos e a perspectiva de formação profissional dos graduandos; (3) para a compreensão da Educação Ambiental como objeto de pesquisa acadêmica. Em todos esses casos, pesquisas precisam ser realizadas para que essas possibilidades possam ser verificadas.

Recuperando a motivação desse texto, entendemos a disciplina foi importante no contato dos alunos com essa temática, motivando-os a desenvolverem seus TCC's e continuar seus estudos nesse tema, fenômeno bastante pontual até então no Instituto de Biologia/UFU, conforme estudos de Barbosa (2016). Nesse sentido, a disciplina busca justificar-se diante dos alunos e do Instituto na qual é ofertada, deixando essa etapa de institucionalização para trás e enfrentando outras, as quais discutiremos mais adiante. 


\section{Os aspectos teóricos da disciplina}

A organização da teoria em uma determinada disciplina acadêmica é um exercício frequente no cotidiano docente. Para tanto, dispomos de nossa experiência como pesquisadores do assunto em questão, das referências bibliográficas dispostas na ficha da disciplina, por vezes lançamos mão de novos referenciais para atualizar nossa ação pedagógica. Essa organização teórica realiza o que é próprio de uma disciplina universitária, ou seja, busca comunicar aos alunos a Ciência a qual se refere aquela disciplina, conforme os autores citados anteriormente.

No caso da Educação Ambiental, a tarefa de determinar e situar a teoria no planejamento da disciplina é desafiadora, uma vez que os fundamentos da temática ainda se encontram em construção. A sua natureza interdisciplinar, o que implica até na discussão sobre a possibilidade ou não dessa temática como campo de conhecimento, ainda é pouco discutida na academia se constitui como um grande desafio para o desenvolvimento da Educação Ambiental. Tal condição é compreensível, afinal, a natureza interdisciplinar da Educação Ambiental se apoia no debate da complexidade, o qual ocorre dentro do processo de mudança paradigmática na Ciência (REIGOTA, 2007; VASCONCELLOS, 2002).

Apesar do desafio apresentado, a organização teórica da disciplina é fundamental porque implica no estabelecimento do pano de fundo no qual o trabalho pedagógico é desenvolvido. Convém ressaltar também que a construção de conceitos e conteúdos da Educação Ambiental é uma atribuição das universidades, conforme orientação do Seminário Regional de Educação Ambiental em Budapeste, na Hungria, em 1983. Cabe à universidade, é responsabilidade dela $\mathrm{o}$ aprofundamento sobre esse tema social e a sistematização do mesmo para fins pedagógicos.

Apresentamos alguns tópicos que temos escolhido para 0 planejamento teórico da disciplina: a relação homem e natureza, Ciência Moderna e a trajetória histórica da Educação Ambiental; as concepções de Educação Ambiental dos alunos e a identificação destes com as tendências da temática; a Educação Ambiental nos espaços formal e não formal de educação; os Estudos Culturais e a influência da mídia, todos esses elementos perpassados pela multiplicidade conceitual própria da Educação Ambiental: desenvolvimento sustentável, sociedade sustentável, conservacionismo, preservacionismo, hedonismo, modernidade, pós-modernidade, ecologia espiritualista, nova era, conspiração de aquário, hipótese de gaia, capitalismo tardio, teologia da libertação, racionalismo, racionalidade instrumental, desenvolvimento convencional, desenvolvimento alternativo, desenvolvimento endógeno, ecodesenvolvimento, globalização, pegada ecológica, mundialização, agroecologia, ecopedagogia, sociedade de risco, gestão ambiental, índice de vulnerabilidade socioambiental (IVSA), agrofloresta, etc.

O desafio do olhar sobre a teoria também implica em dialogar com as atividades práticas. É o que Leff (2001) chama de novos objetos 
interdisciplinares, os quais se constituem na convergência e amalgama entre o saber científico e o saber prático das comunidades. Para o autor citado, devese oportunizar um "processo de pesquisa em conjunto com as comunidades e populações nas quais existem os problemas ambientais, captando os problemas a partir das bases e devolvendo a elas o saber elaborado para sua aplicação" (LEFF, 2001, p. 221). Do ponto de vista ideal, entendemos por atividades ou parte prática da disciplina de Educação Ambiental, a execução de um projeto junto à comunidade ou a escola. Do ponto de vista real, nem sempre é possível desenvolvê-la. Assim, vale questionar sobre os limites dessa atividade prática dentro do tempo disponibilizado por uma disciplina acadêmica, em média 60 horas. Considerando que o envolvimento com uma comunidade ou uma escola leva algum tempo de modo para que se obtenham boas condições relacionais para o desenvolvimento de uma proposta, a carga horária citada pode ser insuficiente. Diante dessas duas dimensões - teoria e prática, uma segunda disciplina de Educação Ambiental dentro da grade curricular pode ser uma possibilidade.

\section{Estratégias de abordagem da parte teórica}

A estrutura desse tópico é formada pela discussão metodológica dos elementos teóricos apresentados anteriormente.

\section{Relação homem e natureza, Ciência moderna e Trajetória histórica da Educação Ambiental.}

A introdução da disciplina poderá ser decisiva para o envolvimento da turma nas atividades propostas, uma vez que os alunos procuram avaliar as condições que possuem para o acompanhamento das propostas apresentadas pelo professor. Além da exposição teórica, comum nos cursos de graduação, outras estratégias podem ser utilizadas para provocar uma reflexão do aluno sobre a relação homem e natureza, ciência moderna e trajetória histórica da Educação Ambiental. Atualmente podem ser encontradas uma diversidade de recursos como livros, textos, filmes, músicas, documentários, dinâmicas de grupo, plataformas eletrônicas etc.

Um dos primeiros movimentos da disciplina é apresentar a Ecoteca Digital (http://www.terrabrasilis.org.br/ecotecadigital/), na qual os graduandos podem se registrar e acessar gratuitamente um grande número de obras relacionadas à questão ambiental e à Educação Ambiental. Além de registrar por escrito sua impressão da ferramenta digital, apresentamos alguns elementos sobre o que prestar a atenção em uma obra: (1) olhar o sumário do livro de modo a atentar se algum capítulo chama sua atenção; (2) verificar no final do livro, podem haver fontes importantes como glossários e outras informações que podem contribuir esclarecer um termo ou enriquecer uma produção escrita.

Destacamos o livro Verde Cotidiano (2008), organizado pelo professor 
interessantes sobre as condições históricas que resultaram no advento da Educação Ambiental. Nesse livro, a discussão do capítulo $A$ natureza na Colonização do Brasil, de Ronald Raminelli, produziu excelentes resultados na discussão sobre as três tragédias ecológicas - agricultura, pecuária e mineração, que marcaram e ainda marcam a história brasileira, note-se as questões que temos proposto:

$\checkmark$ Quais as principais ideias do texto?

$\checkmark$ O grupo concorda com essas ideias? Justifique sua resposta.

$\checkmark$ Na visão do autor, qual a importância da cultura na preservação do meio ambiente?

$\checkmark$ As três catástrofes ecológicas citadas no texto podem ser consideradas fatos do passado? Justifique sua resposta.

$\checkmark$ O Brasil passou por outras catástrofes ecológicas além das que foram citadas pelo autor? Em caso positivo, cite e comente.

Convém ressaltar que 0 aluno tem direito ao saber, se nos permite dizer o saudoso Anísio Teixeira. Assim, cada professor selecionará os textos para a disciplina, destacamos algumas fontes que avaliamos como pertinentes: (1) O âmago da sustentabilidade (VEIGA, 2014); (2) Educación ambiental: trayectorias, rasgos y escenarios (GONZÁLES GAUDIANO, 2007); (3) Da pessoa ao planeta (ALPHANDÉRY, 1992).

Recentemente temos promovido uma situação com o objetivo de prepará-los para a produção de opinião no ambiente virtual. Diante de uma imagem fotográfica viralizada nas redes sociais - a de fãs aguardando Jhonny Depp para o lançamento de um de seus filmes, na qual apenas uma senhora não está com o celular - os alunos são convidados a elaborar uma postagem para um blog de sua própria autoria. Essa simulação ocorre em dois momentos da disciplina, um no início e a outra mais adiante no semestre. A primeira imagem refere-se ao tema consumismo de aparelhos celulares, os colegas da turma são convidados a ler e comentar a postagem. A segunda imagem referese reportagem viralizada nas redes sociais sobre a falta de educação dos visitantes revelada no dia seguinte à inauguração do Museu do Amanhã, na cidade do Rio de Janeiro. Os alunos apresentam sua postagem para a apreciação dos pais, amigos e cônjuges dos alunos. Além de buscar a utilização refinada de conceitos e vocábulos específicos da área ambiental, os resultados vêm chamando nossa atenção para a intolerância dos alunos para com o homem, aspecto que recuperamos logo a seguir, com a discussão das tendências da Educação Ambiental. 


\section{Concepções de Educação Ambiental dos alunos e as tendências da temática.}

A investigação das concepções dos alunos sobre Educação Ambiental e a correlação dessas concepções às principais tendências da temática podem ser um dos objetivos no programa de trabalho do professor. As tendências da Educação Ambiental consideradas para a disciplina em questão foram sistematizadas em nosso estudo de doutoramento, a saber: Educação Ambiental Tradicional; Educação Ambiental para resolução de Problemas; Educação Ambiental Integradora e Educação Ambiental para Transformação Social.

Logo no início da disciplina, solicitamos aos alunos a redação espontânea com o seguinte título: Sobre Educação Ambiental. Ao longo do semestre, novas edições deste texto são realizadas pelos alunos, sendo uma delas acompanhadas de aproximadamente 80 livros que disponibilizamos na sala de aula. Em geral, a última versão contém uma escrita mais amadurecida, sobre a qual realizamos um parecer e devolvemos aos alunos. Ao escrever, desenhar ou até mesmo fotografar sobre Educação Ambiental, a concepção dos alunos podem ser submetidas à identificação com alguma das tendências a eles apresentadas ou mesmo uma mudança de tendência. Com o mesmo objetivo solicitamos a resenha de um dos capítulos do livro Identidades da Educação Ambiental Brasileira, publicado em 2004, produzido pelo Ministério do Meio ambiente (MMA) e disponível na internet.

O desconhecimento da maioria absoluta dos alunos sobre as diversas tendências da Educação Ambiental justifica a importância de sua abordagem. Entendemos que é o eixo em torno do qual as demais atividades da disciplina poderão ocorrer.

\section{Educação Ambiental em espaços de educação formal e não formal}

A discussão sobre experiência dos alunos com a Educação Ambiental desde a Educação Básica ao Ensino Superior a partir das próprias experiências e reflexões dos alunos pode ser pertinente ainda que, na maioria dos casos, fique evidente a ausência do tema na formação dos alunos até aquele momento.

Mas o que chama a atenção dos graduandos é o recente desenvolvimento da Educação Ambiental que vem ocorrendo em espaços de educação não formal como as Organizações não governamentais (ONG's), museus, parques públicos e privados, zoológicos, jardins botânicos, reservas florestais, departamentos de gestão e Educação Ambiental em empresas privadas, etc. Para essa abordagem, o estudo dos textos Análise do potencial pedagógico de espaços não-formais de ensino para o desenvolvimento da temática da biodiversidade e sua conservação (PIVELLI; KAWASAKI, 2005) e A Agenda 21 como instrumento para gestão ambiental (KOHLER; PHILLIPPI JR., 2003) tem produzido bons resultados como o mapeamento ambiental dos 
espaços não formais da própria cidade do graduando. Outra ferramenta que tem sido bem recebida pelos alunos é a apresentação e discussão sobre o Sistema Nacional de Unidades de Conservação (SNUC).

No decorrer dos anos de docência nessa disciplina, percebemos que a mesma pode exercer um papel importante no início do curso pois, para além das carreiras de pesquisador na universidade e docência na educação básica, apresenta aos alunos o temos chamado de setor ambiental, o qual se constitui em um conjunto de novas oportunidades profissionais oferecidas pela sociedade aos graduados e pós-graduados para atuarem individualmente ou coletivamente nas áreas de Gestão e/ou Educação Ambiental. Além da criação de departamentos ambientais pelas empresas privadas e públicas, muitos espaços de educação não formal como museus, parques, jardins botânicos, oceanários, planetários, zoológicos, reservas ecológicas dentre outros estão adotando uma perspectiva proativa em relação aos seus visitantes.

\section{Os Estudos Culturais e a influência da mídia}

A contribuição dos Estudos Culturais para o trabalho pedagógico da Educação Ambiental vem se consolidando pela crescente produção científica que se observa nos periódicos e congressos sobre Educação Ambiental. Assim, com fins de educar sobre o meio ambiente, relevantes trabalhos (GUIMARÃES, 2009; KAUFFMANN, 2009; SAMPAIO; WORTHMANN, 2004) têm sido desenvolvidos no sentido de perceber quais os discursos e os interesses presentes nos elementos midiáticos contemporâneos. Esses resultados de pesquisa podem ser pertinentes para a compreensão dos Estudos Culturais na Educação Ambiental. Caso seja objetivo do professor que os Estudos Culturais perpassem todo o trabalho da disciplina, este deve explicitar aos alunos o corpo teórico dessa abordagem, utilizando para tanto textos que apresentem e discutam seus fundamentos. O livro Ensaios em Estudos Culturais, Educação e Ciência, organizado pela profa. Dra. Maria Lúcia Castagna Wortmann, publicado em 2007, pode ser uma ferramenta importante para a compreensão desse campo de conhecimento.

\section{Outras atividades relacionadas aos itens anteriores}

A verificação e discussão da Pegada ecológica (Ecological Footprint) (https://www.footprintnetwork.org) de cada graduando tem se revelado bastante pertinente, pois podemos identificá-la como um elemento da segunda tendência da Educação Ambiental apresentada, a Resolução de Problemas e também discuti-la como uma ferramenta a ser utilizada nos espaços de educação formal e não formal nos quais se deseja desenvolver uma prática de Educação Ambiental, conforme recomendam Brites (2016); Fidelis (2013); Amaral (2010). Além da recomendação dos autores, outra justificativa para a abordagem dessa ferramenta na disciplina encontra-se no fato de que os ingressantes denunciam que passam pela Educação Básica sem ouvir falar da Pegada Ecológica. A essa justificativa, soma-se o fato de que veteranos do 
curso de Engenharia Ambiental, matriculados na disciplina em questão, também relatam desconhecer 0 assunto.

A utilização de filmes relacionados à questão ambiental também tem se revelado como uma estratégia pertinente para 0 trabalho educativo. Apresentamos e comentamos uma lista com 13 títulos, dentre os quais os alunos devem escolher um para apresentar o potencial pedagógico para a Educação Ambiental. O potencial pedagógico refere-se aos temas abordados pelo filme, as séries escolares para as quais deve ser exibido, os limites da obra que devem ser observados pelo professor, etc... Além dessa tarefa, o graduando também deve escolher um filme de seu próprio repertório e elaborar também um parecer. Assim, a atividade prevê dois pareceres. Três textos, todos disponíveis na internet, foram oferecidos como subsídios para os alunos: (1) Os filmes e os estudos de Educação Ambiental; (2) O cinema como componente didático da Educação Ambiental; (3) O filme wall-e como recurso didático nas aulas de filosofia: contribuindo para a Educação Ambiental de alunos do ensino médio. Os títulos apresentados são: Erin Brockovich (2000); Koyannisquatsi (1983); Amazônia em Chamas (1994); Nas montanhas dos gorilas (1988); A era da estupidez (2009); O Lórax (2012); Homem urso (2006); Flow (2008); O grande milagre (2012); Consumed (2015) Wall-e (2008), Entre rios (2009) e Os Croods (2013). Os resultados dessa ação pedagógica foram surpreendentes, os alunos não conheciam a maioria dos filmes apresentados, por isso assistiram vários ao longo do semestre. Alguns comentaram de que as obras contribuem para a percepção das tendências da Educação Ambiental. Mais recentemente, temos utilizado uma plataforma eletrônica com 56 títulos de filmes em Educação Ambiental: https://sites.google.com/view/guia-filmeseducacaoambiental.

Recentemente temos trabalhado com músicas para Educação Ambiental. Utilizando plataformas eletrônicas como youtube e vagalume, exibimos, lemos e discutimos um total de 12 músicas que nos últimos 20 anos abordaram o tema meio ambiente, direta ou indiretamente. São elas: Absurdo, de Vanessa da Matta; As árvores, de Arnaldo Antunes; Bichos do mar, de Lenine; Panorama Ecológico, de Erasmo Carlos; Passaredo, de Chico Buarque; Sobradinho e Estrela Natureza, de Sá e Guarabira; Xote Ecológico, de Luiz Gonzaga; Herdeiros do futuro, de Toquinho; Rosa de Hiroshima, de Vinícius de Moraes; Fábrica, de Renato Russo e Terra, de Caetano Veloso. Chama nossa atenção o fato recorrente dos alunos do primeiro período não conhecerem nem uma das músicas listadas, com exceção de um ou outro estudante, o que nos leva a solicitar que pesquisem e apresentem por escrito uma música para ser acrescentada à lista exibida em sala de aula.

A atividade Aprofundamentos consiste na discussão em grupos de uma série de questões que fomos elaborando no decorrer de nossa prática docente e permitem uma avaliação do desenvolvimento da turma. Destacamos algumas: 
$\checkmark$ Qual a explicação para a questão ambiental (o código florestal, a usina de Belo Monte, por exemplo) não fazer parte dos temas das manifestações públicas ocorridas em Junho de 2013, no Brasil? Considerando que a maior parte dos manifestantes eram universitários, que atitudes poderiam ser tomadas pelas instituições formadoras?

$\checkmark$ Nesse momento assistimos uma propaganda na TV, valorizando a pessoa do agricultor, um tipo de educação para o reconhecimento de seu papel na alimentação da população, o que é evidente e compreensível. No momento em que a bancada ruralista comemora o novo código florestal, é possível que a mídia acabe contribuindo para a alienação da população em relação a esse fato lamentável na história do país? Comente sua resposta!

$\checkmark$ Em recente participação no Programa do Jô, Rosana Jatobá, exapresentadora da Rede Globo, afirmou que seu envolvimento com a sustentabilidade ocorreu a partir do contato que teve com o documentário Uma verdade inconveniente, do americano Al Gore. Entretanto, atualmente considera que a Educação Ambiental não se faz pela ameaça da desgraça anunciada pelo documentário, e sim pela sedução para a conscientização. Como devemos nos portar diante dessas ênfases, no que se refere à prática da Educação Ambiental hoje?

$\checkmark$ Considerando que mais de 100 municípios brasileiros já inseriram, via câmara de vereadores, uma disciplina de Educação Ambiental na Educação Básica, vale perguntar: $A$ disciplina deve ser ministrada por professor de qual área? Os estagiários do curso de licenciatura em Ciências Biológicas poderiam realizar seus estágios de regência nessa disciplina?

$\checkmark$ Elabore a página inicial de um site de uma ONG, evidenciando uma das quatro tendências de Educação Ambiental. Tendência escolhida: (_).

Os seminários temáticos ocorrem no final da disciplina e representam, em nossa percepção, um momento de convergência do que foi desenvolvido durante o semestre. São apresentados sete temas: (1) Novo Código Florestal, discute-se os impactos sócio-ambientais da nova legislação e a repercussão internacional; (2) Ambientalistas/Ecólogos/Ecologistas, o objetivo é identificar personalidades locais e nacionais, bem como a compreensão clara dos três vocábulos; (3) Mídia, a intenção é oportunizar aos colegas uma discussão sobre o serviço/desserviço da mídia no que tange à questão ambiental; (4) Agroecologia, o grupo busca apresentar a franca expansão dessa área dentro e fora da universidade; (5) Greenwashing, além da definição do assunto, o grupo exemplifica situações cotidianas por ocasião do consumo de produtos; (6) Organização Não Governamental (ONG), o objetivo pode ser apresentar os passos para formação de uma ONG até a discussão sobre a presença/ausência de ONG's locais; (7) Política nacional de resíduos Sólidos (PNRS), o grupo aborda a recente publicação da lei que instituiu a PNRS e seus impactos locais. 
Apresentados os temas, os alunos escolhem em qual grupo participar. No primeiro encontro de preparação, oferecemos um texto relacionado ao assunto daquele grupo para que possam ter um aporte teórico sobre o assunto. A preparação dos seminários ocorre principalmente em sala, com a participação do professor e do monitor da disciplina. Os resultados dessa atividade evidenciam os alcances da disciplina ao longo do semestre e contribuem para a preparação da nova oferta no semestre seguinte.

Cabe mencionar a proposta para a semana do meio ambiente, quando a disciplina é oferecida no primeiro semestre do ano. São oferecidos aos alunos a programação da prefeitura, das universidades e das associações de bairro do município e da região, de modo que possam escolher pelo menos uma para participar e depois resenhar textualmente sobre a mesma. $\mathrm{Na}$ referida semana não há encontro presencial com os alunos, sendo a atividade da semana registrada de forma não presencial. Os resultados são muito promissores, vários conceitos são mobilizados pelos alunos durante as discussões em sala, alguns chegam a dizer que foi uma aula prática da disciplina.

Concluindo esse grupo de atividades, as Histórias em Quadrinhos (HQ's), na forma de tirinhas, são uma oportunidade para discutir importantes elementos como o mito de que a natureza possui vida própria e revida conscientemente em relação à degradação da natureza provocada pela atitude humana e o conceito do que é Educação Ambiental. Dois textos nos acompanham - As histórias em quadrinhos (HQ's) na formação dos professores de Ciências e Biologia, de Melchior José Tavares Júnior, e o de Liliane Ramalho Cordeiro (2006), intitulado Limites e Possibilidades das Histórias em Quadrinhos como mediadora de Educação Ambiental. Esses textos auxiliam os alunos a filtrarem as tirinhas nos aspectos racista, classista, sexista, abordagens religiosas levianas e a incorreção conceitual-científica.

Dentre as 24 tirinhas que semestralmente discutimos com os alunos, destacamos como exemplo:

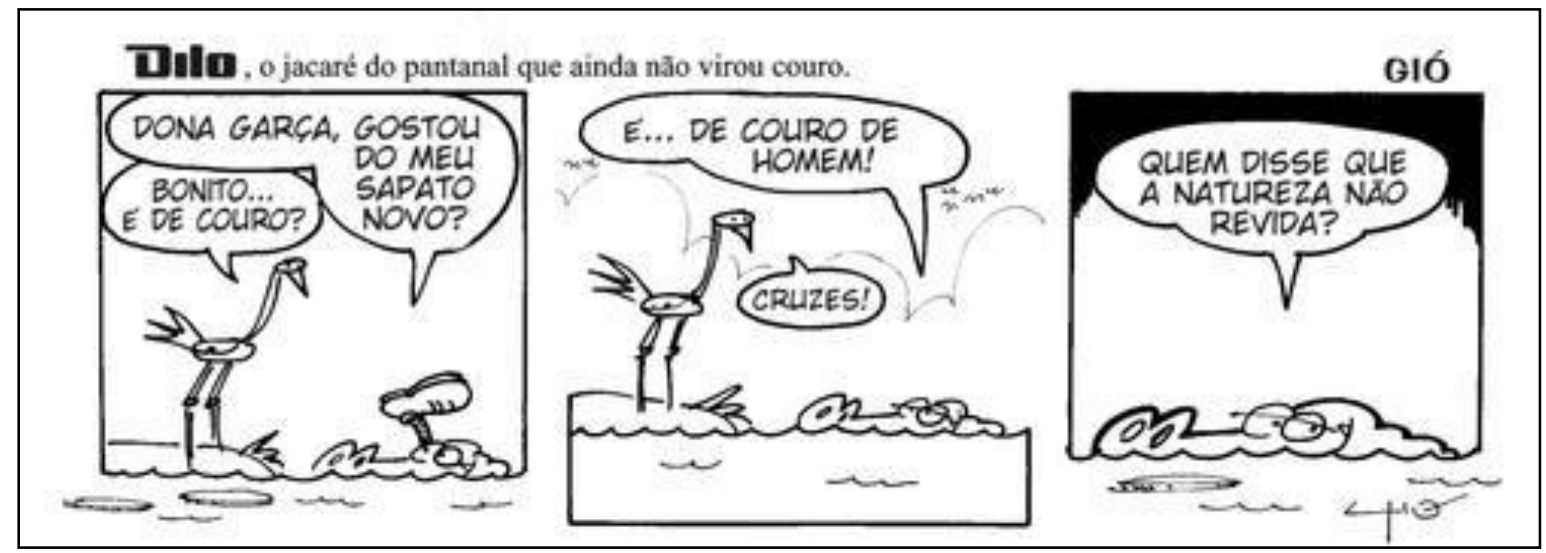

Revbea, São Paulo, V. 15, № 1: 97-115, 2020. 


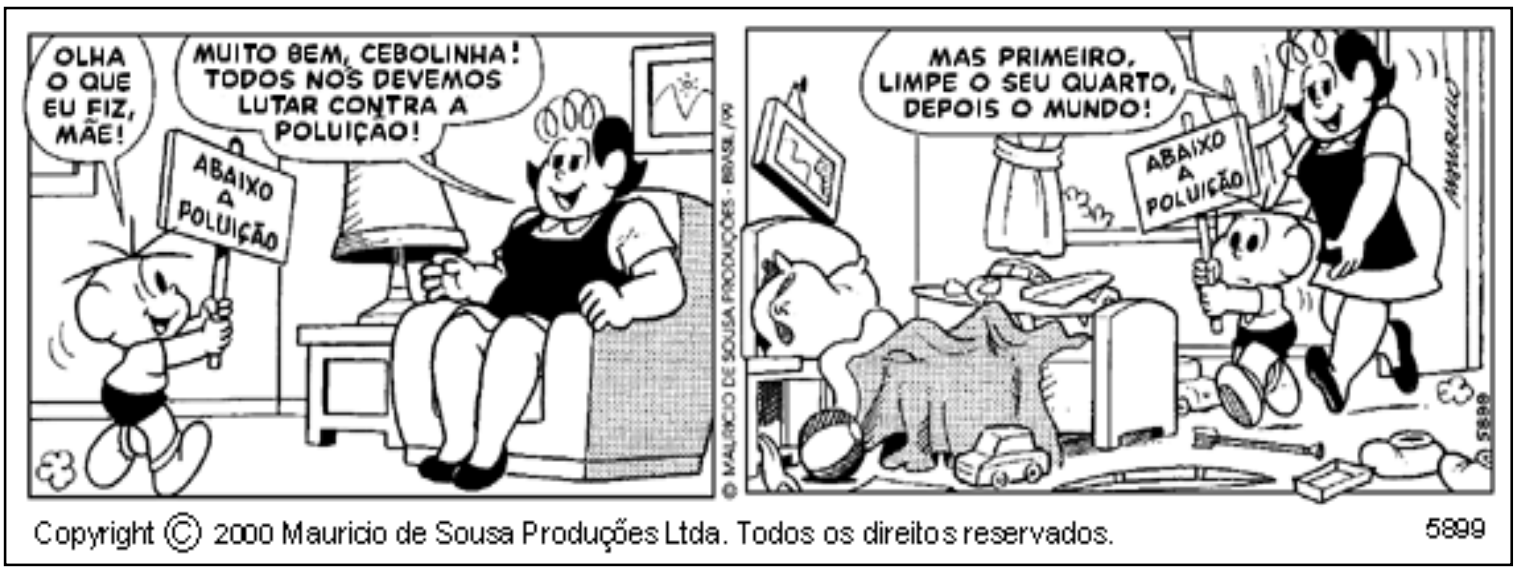

\section{Avaliação e perspectiva da disciplina}

Avaliar a disciplina na formação inicial implica no enfrentamento da provocação de Teixeira; Torales (2014, p. 129):

Diante do avanço da Educação Ambiental na educação básica, o professor é colocado diante de exigências às quais ele responde com dificuldade e para as quais os cursos de licenciatura pouco contribuem. Certo distanciamento dos professores da Educação Ambiental tem como justificativa desde condições de trabalho que dificultam inovações e mais esforços, até a constatação de que não estão preparados para trabalhar com a Educação Ambiental.

Assim, entendemos que é necessária uma resposta à seguinte pergunta: o graduando que passa pela disciplina Educação Ambiental do curso de Ciências Biológicas da UFU recebe formação suficiente para desenvolver o tema na vida profissional? Somente pesquisas de campo poderão responder essa pergunta determinante, objeto que temos nos dedicado atualmente.

O que podemos perceber em nosso cotidiano docente é que a disciplina Educação Ambiental garante o contato sistemático do graduando com o tema, oferecendo uma determinada bagagem teórico-metodológica. Quando oferecida logo no início do curso, vários alunos decidem por este tema em seu TCC, bem como pela continuidade de estudos em nível de mestrado e doutorado nessa área.

Entretanto, se a forma disciplinar deve cumprir aquilo que the próprio ou seja, estabelecer o contato entre estudantes e certa área de conhecimento (SOMMERMANN, 2003; CHERVEL, 1990; SANTOMÉ, 1998), então o princípio interdisciplinar, contido na definição do tema desde 1977, cria um impasse, uma possível limitação para essa forma de abordagem do tema. Assim, uma disciplina só pode ir até um determinado ponto, ou seja, os alunos precisariam ter uma vivência interdisciplinar e não apenas informar-se sobre ela.

Partindo dessa premissa, consideramos que os graduandos de Ciências Biológicas deveriam ter a oportunidade de desenvolver projetos de 
Educação Ambiental com estudantes de outros cursos numa segunda oferta disciplinar. Falamos da inserção de uma disciplina com esse fim, intitulada Projetos de Educação Ambiental, poderia ser interessante desde que possa acolher estudantes de vários cursos de graduação. Por ora, recomendamos 0 estímulo sistemático dessa temática nos projetos nos estágios supervisionados, nos trabalhos de iniciação científica, no Programa Institucional de Bolsas de Iniciação à Docência (PIBID) - principalmente sua versão interdisciplinar e no Programa de Educação Tutorial (PET).

Em relação à avaliação da disciplina pelos alunos, seguem alguns registros espontâneos encontrados no sistema eletrônico de avaliação da universidade:

$\checkmark$ O professor utiliza a disciplina para fazer com que os alunos enxerguem outros aspectos presentes na biologia e que muitas vezes não vemos.

$\checkmark$ A disciplina proporcionou várias discussões que nos enriqueceram além do acadêmico, afetando o social e nos proporcionando reflexões sobre nossas ações. É de extrema importância as "provocações" feitas pelo professor durante as aulas, por meio delas conseguimos ver as falhas do nosso curso e da nossa formação e procurar soluções para as mesmas.

$\checkmark$ Trouxe temas e discussões fundamentais para qualquer graduando de Biologia, que ao longo do curso não são discutidos.

$\checkmark$ Tem atividades muito boas para fazer o aluno crescer intelectualmente. Propõe muitas formas para ajudar os alunos no futuro acadêmico.

$\checkmark$ Aulas sempre dinâmicas, com atividades que os alunos têm prazer em desenvolver, conteúdo chamativo, professor dinâmico e expressivo.

Além do apoio dos alunos, observamos que a Educação Ambiental já não se encontra sozinha no processo de institucionalização do tema no curso de Biologia/UFU. Além de contar com atividades realizadas pelo Programa de Educação Tutorial (PET), recentemente a empresa júnior, alocada no Instituto de Biologia/UFU passou a desenvolver atividades de gestão e Educação Ambiental. Embora vejamos esse panorama com satisfação, não podemos descartar o risco de isolamento desse tema na graduação, falamos em estudo, debate, proposição e tomada de decisão pelas instituições acadêmicas, uma perspectiva mais amadurecida de Educação Ambiental como "nova função social da Educação" (BILERT, LINGNAU, OLIVEIRA, 2014).

Embora nosso saber docente pareça formatado demais, não significa que a referida disciplina, como qualquer outra, não enfrente percalços de toda sorte ao longo do semestre letivo. Destacamos o difícil período de adaptação ao primeiro semestre, principalmente quando o ingressante é de outra cidade. Outra dificuldade é o enfrentamento de matérias das áreas exatas. Além desses fatores, nem todos os alunos se interessam pelo assunto de nossa disciplina, seja ela qual for. Nesse sentido, temos aprendido a respeitar esse graduando e não exigir dele a tradicional devoção pela disciplina ofertada. 


\section{Considerações finais}

O objetivo desse texto foi refletir sobre a disciplina de Educação Ambiental no curso de Ciências Biológicas da UFU por meio do registro do saber docente construído nos últimos anos como professor da disciplina. Consideramos que muitos passos já foram dados como a garantia de acesso ao tema sistematizado, o despertar para a continuidade de estudos e a comunicação de novas oportunidades profissionais para os biólogos. Apesar dos alcances promovidos pela forma disciplinar no atual tempo e espaço, reconhecemos que os limites desse modo de abordagem podem comprometer a prática profissional dos estudantes e deve ser uma discussão permanente nas instituições formadoras. Para o final, o convite para a necessária interlocução com outros colegas está proposto, no sentido de construirmos juntos um saber que seja de fato plural, o mais ajustado possível as necessidades que se apresentam para a constituição do conhecimento em Educação Ambiental.

\section{Referências}

ALENCAR, L. D.; BARBOSA, M. F. N. Educação Ambiental no Ensino Superior: ditames da Política Nacional de Educação Ambiental. Revista Direito Ambiental e sociedade, v. 8, n. 2, 2018, p. 229-255.

ALPHANDÉRY, P. Da pessoa ao Planeta. In: ALPHANDÉRY, P. BITOUN, P. DUPONT, Y. O Equívoco Ecológico. São Paulo: Brasiliense, 1992.

AMARAL, R. C. Análise da aplicabilidade da pegada ecológica em contextos universitários. Escola de Engenharia, Universidade Federal de São Carlos/SP, 2010. Trabalho de conclusão de curso (Monografia). Disponível em: $<$ http://www.tcc.sc.usp.br/tce/disponiveis/18/180300/tce-15022011-145930/?\& lang=br>. Acesso em: 15.05.2018.

BARBOSA, P. C. P.; TAVARES JÚNIOR, M. J. Educação Ambiental no curso de Ciências Biológicas da UFU: a pesquisa e a institucionalização do tema na formação dos biólogos. Anais do VII Encontro Mineiro Sobre Investigação na Escola, Uberlândia/MG, Setembro de 2016.

BRITES, A. BERTUCI, T. C. S. C. Pegada ecológica: um estudo de caso aplicado com os alunos da EJA de uma escola estadual no município de Antônio João - MS. Revista da Sbenbio, n. 9, 2016.

BILERT, V.S.S.; LINGNAU, R.; OLIVEIRA, M.R. A Educação Ambiental nos cursos das ciências sociais aplicadas. Perspectiva, v. 38, n.142, p. 103-113, 2014.

CHERVEL, A. História das disciplinas escolares: reflexões sobre um campo de pesquisa, Teoria e Educação, Porto Alegre, n. 2, p. 177-229, 1990. 
CORDEIRO, L. R. Limites e Possibilidades das Histórias em Quadrinhos como mediadora de Educação Ambiental. Universidade Federal do Rio de Janeiro (UFRJ: Monografia (especialização). Disponível em: <http://www.nebad.ueri. br/publicacoes/monografias/quadrinhos \%20educacao ambiental.pdf >. Acesso em: 05.05.2018.

FIDELIS, G. A. Análise da pegada ecológica de alunos do ensino médio e perspectiva de desenvolvimento sustentável, Revista ea, n. 43, ano XI, 2013.

GONZÁLEZ GAUDIANO, E. Educación ambiental: trayectorias, rasgos y escenarios. México: Plaza y Valdés, 2007.

GUIDO, L. F. E.; TAVARES JÚNIOR, M. J. Pesquisa sobre Educação Ambiental no contexto escolar: a imersão nos ambientes educativos. Pesquisa em Educação Ambiental (Online), v. 4, p. 175-189, 2009.

GUIMARÃES, L. B. Educação Ambiental e Literatura: narrativas sobre as florestas, Cadernos de Educação, Pelotas, n. 34, p. 153-166, set./dez. 2009.

KAUFFMANN, C. Estudos culturais, mídia e meio ambiente: Tecendo saberes para uma cultura ambiental. Anais do V Encontro de Estudos Multidisciplinares em Cultura. Salvador/BA, 2009. Disponível em: <http://www.cult.ufba.br/enecult 2009/19345.pdf>. Acesso em: 07 jul. 2010.

KOHLER, M. C. M.; PHILLIPPI JR. J. A Agenda 21 como instrumento para gestão ambiental. Revista Educação Ambiental e sustentabilidade, n. 3, p. 713-735, 2003.

LAYRARGUES, P. P. Identidades da Educação Ambiental brasileira. Brasília: MMA, 2004.

LEFF, E. Saber ambiental: sustentabilidade, racionalidade, complexidade, poder. Petrópolis: Vozes, 2001.

MARTINS, G. A.; BENAVIDES, M. L. A.; ROMALHO, D. G.; BRANDO, F. D. G. Uma proposta didática para disciplina de Educação Ambiental no Ensino Superior, a partir de concepções prévias sobre "meio ambiente", Tecné, Episteme y Didaxis, (38), p. 57-74, 2015.

PIVELLI, S. R. P.; KAWASAKI, C. S. Análise do potencial pedagógico de espaços não formais de ensino para o desenvolvimento da temática da biodiversidade e sua conservação. Anais do V Encontro nacional de Pesquisa em ensino de Ciências (V ENPEC), 2005.

PRAIA, J. F. CACHAPUZ, A. F. GIL-PÉREZ, D. Problema, teoria e observação em ciência: para uma reorientação epistemológica da educação em ciência. Ciência \& Educação, v.8, n.1, p.127-145, 2002.

REIGOTA, M. Verde cotidiano: o meio ambiente em discussão. Petrópolis: DP\&A, 2008.

REIGOTA, M. O estado da arte da pesquisa em Educação Ambiental no Brasil, Pesquisa em Educação Ambiental, São Carlos, v. 2, n. 1, 2007. 
SAMPAIO, S. M. V.; WORTMANN, M. L. C. Fabricação de educadores/as ambientais e experiências: alguns olhares para a formação de professores/as. 2004. Disponível: <http://www.anppas.org.br/encontro anual/ encontro2/GT/GT10/shaula sampaio.pdf>. Acesso: 04.06.2015.

SANTOMÉ, J. T. Globalização e interdisciplinaridade: o currículo integrado. Porto Alegre: Artes Médicas, 1998.

SCHÖN, D. Educando o Profissional Reflexivo: um novo design para o ensino e a aprendizagem. Porto Alegre: Artmed, 2000.

SOMERMANN, A. Formação e transdisciplinaridade: uma pesquisa sobre as emergências formativas do CETRANS. Dissertação de Mestrado em Ciências da Educação, Faculdade de Ciências e Tecnologia da Universidade Nova de Lisboa, 2003. Disponível em: <http://run.unl.pt/bitstream/10362/400/1/ sommerman 2003.pdf>. Acesso: 25 out. 2010.

TARDIF, M. Saberes docentes e formação profissional. Petrópolis, RJ: Vozes, 2007.

TAVARES JÚNIOR, M. J. Histórias em Quadrinhos (HQ's) na formação do professor de Ciências. Santa Maria/RS, Educação, v. 40, n. 2, maio/ago. 2015, p. $439-450$.

TEIXEIRA, C.; TORALES, M. A.; A questão ambiental e a formação de professores para a educação básica: um olhar sobre as licenciaturas. Educar em Revista, Edição Especial v.3, n. 3, p. 127-144, 2014.

VASCONCELLOS, M. J. E. Pensamento Sistêmico: o novo paradigma da Ciência. Campinas: Papirus, 2002.

VEIGA, J. E. O âmago da sustentabilidade. Estudos Avançados, n. 28(82), p. 7-23, 2014.

WORTMANN, M. L. C. (org.) Ensaios em Estudos culturais, Educação e Ciência. Porto Alegre: Editora da UFRGS, 2007. 